\title{
Recruitment and Rotation of the Trainers in the Lifelong Learning Context
}

\author{
Xhevrie Mamaqi, Pilar Olave Rubio, and Jesús Miguel Alvarez \\ Department of History and Structural Economics (Quantitative Method Area) \\ Faculty of Economics, Zaragoza University, Spain \\ \{mamaqi, polave, jamiguel\}@unizar.es
}

\begin{abstract}
The workplace of today is characterized by rapid changes in work processes, in competition, in customer demands, and in work practices. To keep abreast of these rapid changes employers and employees must be committed to lifelong learning in order to keep ahead. One of the most important actors in the lifelong learning development process are the trainers, whose professional characteristics needs meeting new skills and adapting an varied and specific contents of the current labour market. Affected by the discontinuity and a high rate of job rotation, the recognition of it labour status and basic competence and skills, forms part of the Bologna Process recognized as Vocational Education Training (VET). Sixty in-depth interviews realized to managers of the centres of formation, are used as tools to obtain information about following topics: recruitment strategies, conventional and not conventional routes of the recruitment, rate rotation, qualification and training of the Spanish trainers. The transcription of the interviews achieve that not always exist a previous plan of recruitment, except that it is a question as big centers of formation. Also, the obtained information indicates a high rate of rotation that affects the trainers ones as professionals since there exists the discontinuity of the formative offer on the labour market.
\end{abstract}

Keywords: Job recruitment, job rotation, trainers, lifelong learning. 